\title{
Diagnósticos da escolarização básica: um confronto de perspectivas ${ }^{*}$
}

Alceu Ravanello Ferraro ${ }^{a}$

\section{Resumo}

$\mathrm{O}$ artigo trata das potencialidades e limites de quatro perspectivas teóricas que vêm marcando presença em diagnósticos da escolarização básica: a do sucessofracasso escolar, a da inclusão-exclusão escolar, a da igualdade-desigualdade educacional e a do direito-dívida educacional. O exame crítico da produção científica internacional a partir da década de 1960 sobre o tema, particularmente no Brasil e na França, sugere: a) que a antinomia fracasso-sucesso leva a diagnósticos equivocados da escolarização, por ter ou induzir a ter como pressuposto que cabe ao aluno ou aluna toda a responsabilidade pelo desempenho escolar; b) que o recurso à antinomia exclusão-inclusão escolar requer que se defina com clareza em que sentido se irão utilizar essas categorias e que se tenha presente que a solução para a exclusão é deixar de excluir e não simplesmente incluir; c) por fim, que as perspectivas teóricas mais promissoras são as da igualdade-desigualdade educacional e do direito-dívida educacional, a primeira por ser expressão do princípio da igualdade, e a segunda, por ter nesse princípio o seu fundamento.

Palavras-chave: Escolarização básica. Diagnósticos. Perspectivas teóricas. Política educacional.

\section{Introdução}

Inicia-se este trabalho com três esclarecimentos. $\mathrm{O}$ primeiro é que o termo diagnóstico é tomado, aqui, como a primeira etapa do ciclo de formulação de uma política pública (de Educação Básica, no caso), etapa esta que é seguida da formulação, implementação e avaliação dessa mesma política. A justificativa é simples: "Afinal, é preciso ter um retrato tão amplo e detalhado quanto possível acerca da situação social vivenciada pela população para orientar, posteriormente, as questões prioritárias a atender, os formatos dos

\footnotetext{
Trabalho realizado dentro de projeto de pesquisa para o período 2015-2020, que conta com bolsa de pesquisador 1-A do Conselho Nacional de Desenvolvimento Científico e Tecnológico - CNPq.

a Universidade Federal do Rio Grande do Sul. Rio Grande do Sul, Porto Alegre, Brasil.
} 
programas a implementar e ações a desenvolver" (JANNUZZI, 2005, p. 148). Obviamente, este sentido difere radicalmente daquele que o termo tem na área da saúde, isto é, de "arte de conhecer as doenças pelos seus sinais e sintomas" (KOOGAN; HOUAISS, 1999), mesmo que este entendimento continue a ser frequentemente transferido para o estudo da sociedade, como se esta fosse um organismo social ${ }^{1}$.

O segundo ponto a esclarecer é que se toma Educação Básica no sentido que essa expressão tem na Lei $n^{\circ}$ 9.394/96 (BRASIL, 1996), compreendendo a Educação Infantil, o Ensino Fundamental e o Ensino Médio.

O terceiro aspecto a deixar claro é que se trata de estudo teórico, compreendendo levantamento e exame crítico da produção científica internacional, especialmente brasileira e francesa, daquilo que se considera serem as quatro perspectivas teóricas mais comuns em diagnósticos da Educação Básica: a da inclusãoexclusão, a da igualdade-desigualdade, a do direito-dívida e a do sucessofracasso educacional. Não se irá, portanto, desenvolver aqui pesquisa empírica, nem mesmo de atualização de estatísticas, mas simplesmente expor e discutir perspectivas teóricas que possam subsidiar estudos empíricos, fundamentados especialmente em Censos Demográficos, em Pesquisas Nacionais por Amostra de Domicílios (PNADs) mais recentes e em Censos Escolares, com vista, por exemplo, à avaliação do grau de universalização da escolarização das pessoas de 4 a 17 anos.

Dito isto, pode-se anunciar que o objetivo deste trabalho é identificar, caracterizar e confrontar entre si as principais perspectivas teóricas que vieram disputando lugar na pesquisa diagnóstica da Educação Básica nas últimas décadas, discutindo-se também as potencialidades e os limites de cada uma delas. Tais perspectivas podem ser postas na forma das antinomias sucessofracasso escolar, inclusão-exclusão escolar, igualdade-desigualdade educacional e direito-dívida educacional. Mas, vista a coisa pelo lado problemático, que é o que mais interessa, pode-se também designá-las como perspectivas do fracasso escolar, da exclusão escolar, da desigualdade educacional e da dívida educacional. A ordem de exposição, porém, não será exatamente esta. O fato de a perspectiva do fracasso escolar ter tomado novo fôlego neste início do século XXI aconselha a deixá-la para exame em último lugar. Inicia-se, assim, pela perspectiva da exclusão escolar.

Herbert Spencer (1820-1903) falava em "analogia entre uma sociedade e um organismo", mas, na realidade, ia muito além da analogia ao apontar as razões pelas quais considerava que uma sociedade é "um organismo" e que "qualquer organismo com uma dimensão apreciável é uma sociedade" (1989, p. 204). 


\section{A perspectiva da exclusão escolar}

Para situar a questão, recorre-se a alguns artigos e livros publicados na França na década de $1990^{2}$, a começar por artigo de Donzelot e Roman (1991, p. 5) sobre o que eles denominam deslocamento da questão social. Segundo os autores, o tema da exclusão suscitara debates já no início da década de 1970, mas referindo-se, então, aos esquecidos do crescimento, como em Les Exclus (Os excluídos), de René Lenoir (1974); somente a partir do início dos anos 1980 o termo exclusão passou a significar não mais uma omissão involuntária, mas uma solução deliberada, de sorte que, se a questão era modernizar, havia que "reduzir os efetivos, só conservando os indivíduos capazes de servir às mutações tecnológicas e rejeitando os outros, todos os outros". (DONZELOT; ROMAN, 1991, p. 5).

Nesse mesmo ano, o sociólogo Touraine (1991) surpreendia com a polêmica tese de que o paradigma de classes, vertical, centrado na perspectiva upper-down (em cima-embaixo, dominantes-dominados), teria cedido lugar ao paradigma da exclusão, de dimensão horizontal, focalizando a perspectiva in-out (dentrofora), tese esta que, anos depois, seria objeto de discussão também no Brasil, como se verá adiante.

No ano seguinte, Bourdeu e Champagne (1992) criavam a categoria excluídos do interior, que compreende os excluídos que ainda se encontram dentro da escola. No mesmo ano, em artigo publicado em número especial da revista Esprit (1992), intitulado La France de l'exclusion (A França da exclusão), Foucault (1992) perguntava se desigualdades e exclusões são da mesma natureza.

Decorridos alguns anos, era publicada a volumosa coletânea L'exclusion: l'état des savoirs (A exclusão: o estado do conhecimento), em que, já na Introdução, o seu organizador observava que, na França, nos dez anos anteriores, a exclusão se tornara uma noção familiar, quase banal (PAUGAM, 1996). Esse mesmo ponto de vista era sustentado por outros participantes da coletânea, como Merrien (1996, p. 417), para quem o termo exclusão estava "longe de representar um objeto claramente identificável, universalmente reconhecido", não sendo mais que "um termo simbolicamente codificado", que repousava sobre o agrupamento de categorias heterogêneas de populações cuja única característica comum era a de se encontrarem fora de algum processo central da sociedade, tal como ocorria com os desempregados e idosos no campo do trabalho, com imigrantes na sociedade

São de inteira responsabilidade do autor deste artigo as traduções do francês, inglês e espanhol das citações dos livros, artigos ou capítulos de livros de Bourdieu e Passeron (1985), Bourdeu e Champagne (1992), Coleman (1970), Condorcet (1792), Donzelot e Roman (1991), Dubet (1996), Foucault (1992), Gournay (1622), Keynes (1925), La Barre (2011), Merrien (1996), Michaels (2009), Noack (1993), Paugam (1996), Perrenoud (1989), Thomas (1997) e Touraine (1991). 
nacional etc., e Dubet (1996, p. 497), o qual, pensando em soluções para a exclusão escolar, dizia que a exclusão social "é menos um estado do que um processo"; que ela "procede de mecanismos que fabricam os supranumerários" e que, em relação à exclusão escolar, mais que dar números e descrever as populações escolares excluídas, o que se deveria descrever e compreender é o mecanismo que produz tal exclusão.

Aparecia, em seguida, um livro sobre a produção dos excluídos, em que Thomas (1997, p. 1, grifos da autora) sustentava que, "mesmo que saturada de senso, de não senso e de contrassenso", a exclusão é uma noção fundamental para a análise sociológica. Dubet $\left(2003^{3}\right.$, p. 43$)$, por sua vez, referindo-se especificamente à relação entre escola e exclusão, dizia que "a exclusão escolar é o resultado 'normal' da exclusão de uma escola democrática de massa que afirma, ao mesmo tempo, a igualdade dos indivíduos e a desigualdade de seus desempenhos" e que, nesse sentido, "a escola integra mais e exclui mais do que antes, apesar de seus princípios e de suas ideologias, e funciona cada vez mais como o mercado, que é, em sua própria lógica, o princípio básico da integração e da exclusão".

Embora não constituindo novidade, parece que se pode dizer que o ponto alto do tema da exclusão na França se deu na década de 1990. No Brasil, no campo da educação, o tema da exclusão data pelo menos de meados da década de 1980. Assim, por exemplo, em estudo que tratara da produção de novos analfabetos na perspectiva da exclusão tem-se:

E essa produção de novos analfabetos se faz através da exclusão praticada pelo aparelho escolar. São vítimas dessa exclusão: 1) todos aqueles que são excluídos in limine, os que nem sequer chegam a ser admitidos no processo de alfabetização na idade de escolarização obrigatória; 2) aqueles que, tendo sido admitidos, são posteriormente excluídos do processo; 3 ) aqueles que, ainda dentro do sistema de ensino, estão sendo objeto de exclusão no próprio processo de ensino através da reprovação e repetência e estão sendo assim preparados para posterior exclusão do processo. A exclusão praticada no processo de alfabetização, através da reprovação e repetência, alimenta, no momento seguinte, através do que eufemisticamente se denomina de evasão escolar, o contingente dos excluídos do processo (FERRARI ${ }^{4}$, 1985, p. 49).

\footnotetext{
3 Artigo publicado originalmente na França em 2001/2002.

4 Em 1992, o sobrenome do autor deste artigo foi retificado, passando de Ferrari para Ferraro.
} 
Mas foi em artigo publicado dois anos depois que o conceito de exclusão escolar foi desdobrado com maior clareza nas categorias exclusão da escola, compreendendo "os que nunca ingressaram na escola e os que, ainda na faixa de 7 a 14 anos, já foram dela excluídos", e exclusão na escola, que "tem a ver diretamente com o próprio processo de alfabetização e costuma ser obscurecida por expressões como baixo rendimento, fracasso escolar, reprovação, recuperação, repetência", sendo que, aqui, "os excluídos ainda estão na escola, ainda em processo de escolarização" (FERRARI, 1987, p. 93). O já referido conceito de excluidos do interior, que apareceria alguns anos mais tarde (BOURDIEU; CHAMPAGNE, 1992), parece coincidir com o de excluídos na escola.

Foi a perspectiva da exclusão que deu sustentação a toda uma série de estudos publicados no Brasil a partir do final da década de 1990, a começar por artigo em que Rosemberg $(1999$, p. 7), referindo-se à expansão ocorrida no governo Geisel e em desdobramentos posteriores, identificava o que ela chamava de "novos processos de exclusão criados pela política de 'democratização' da educação infantil”, e outro em que o autor deste artigo (FERRARO, 1999) desenvolvia uma série de análises estatísticas sobre escolarização com apoio nas categorias de excluídos da escola, excluídos na escola e incluídos na escola.

Mas o tema da exclusão foi também objeto de discussão e crítica. Criticou-se a pretensa "novidade" do termo exclusão no novo sentido identificado no texto já citado de Donzelot e Roman (1991), de ação deliberada de redução de efetivos, argumentando-se, de um lado, que a exclusão é fenômeno tão velho como a humanidade (RIBEIRO, 1999) e, de outro, que esse significado já aparecia claramente formulado na obra de Marx (OLIVEIRA, 2004).

Criticou-se particularmente a tese de Touraine (1991), de que o paradigma da exclusão teria vindo em substituição ao paradigma de classes, argumentando-se que a categoria exclusão, longe de constituir um novo paradigma, só poderia ganhar alcance na medida em que viesse articulada com o conceito de classe social (RIBEIRO, 1999; OLIVEIRA, 2004). Essa crítica, aliás, já aparecera alguns anos antes na França:

Os partidos de esquerda mantinham-se cautelosos quanto ao uso desta noção de exclusão, seja porque ela remetia, pelo menos indiretamente, à ideia de lumpemproletariado, suscetível, segundo Marx e Engels, de acabar com a revolução, seja porque, ao menos no entendimento de Lenoir, ela se afastava de uma visão dialética 
da luta de classes. Por todas estas razões, a noção de exclusão foi prontamente rejeitada (PAUGAM, 1996, p. 11).

No entanto, como observa Paugam (1996, p. 17), isso não impediu que, a partir da década de 1980, a noção de exclusão passasse a ser usada de maneira consensual, "tanto pela esquerda como pela direita", mas tornando-se "cada vez mais fluida e equívoca como categoria científica".

Oliveira (2004, p. 151 e 153), por sua vez, procurou mostrar que "o conceito de exclusão não é capaz de consubstanciar um novo paradigma social", e que a vocação mais clara da ideia de exclusão é "funcionar como conceito descritivo".

Daí a necessidade de que qualquer trabalho de investigação empírica sobre o tema venha acompanhado de sólida discussão teórico-conceitual a respeito, particularmente, sobre o alcance da noção de exclusão e sobre como enfrentar o problema da exclusão escolar. A antinomia exclusão-inclusão já traz embutida a ideia de que a solução do problema deve ser buscada em processos de inclusão. É nessa lógica que se fundamenta a "onda da inclusão" que se seguiu à "onda da exclusão". No entanto, de que valeria incluir numa escola excludente, isto é, que continuasse regendo-se pela lógica da exclusão? Como bem observa Oliveira (2004, p. 76), em termos dialéticos, a solução deve ser buscada na negação da negação, isto é, na "exclusão da exclusão". Forma mais precisa de se dizer o que fora antecipado quase duas décadas antes: "se o que temos [na escola brasileira] é exclusão socialmente produzida, a solução é deixar de excluir". Para tal "o primeiro passo é a vontade política de não mais excluir, de repartir o saber igualmente entre todos, de universalizar o acesso à escola e de estender a todos as condições de permanência e progressão na escola" (FERRARI, 1987, p. 96).

Essa ideia de universalização da educação escolar não é nova, tendo tido sua primeira formulação mais consistente no Relatório e projeto de decreto sobre a organização geral da instrução pública..., apresentados, na França, pelo marquês de Condorcet à Assembleia Nacional, em nome do Comitê de Instrução Pública em 20 e 21 de abril de 1792. Nesse documento se lê, logo no início, que a primeira finalidade de uma instrução nacional, que é, para o poder público, "um dever de justiça”, consiste em:

Oferecer a todos os indivíduos da espécie humana os meios de prover às suas necessidades, de assegurar o seu bem-estar, de conhecer e de exercer os seus direitos, de compreender e de cumprir os seus 
deveres; garantir a cada um deles a possibilidade de aperfeiçoar a sua habilidade, de se capacitar para as funções sociais às quais ele tem direito de ser chamado, de desenvolver em toda sua extensão os talentos que recebeu da natureza, para, assim, estabelecer entre os cidadãos uma igualdade de fato e tornar real a igualdade política reconhecida pela lei (CONDORCET, 1792, p. 2).

Essa ideia de universalização da instrução pública, presente com tanta força no liberal Condorcet no imediato pós-Revolução Francesa, esteve sempre longe de ser consenso dentro do liberalismo. Ela reaparece com força, neste início do século XXI, em A educação para além do capital, no qual Mészáros (2010) diz que, para a efetiva transcendência da autoalienação do trabalho, há que colocar em primeiro plano dois conceitos fundamentais: "A universalização da educação e a universalização do trabalho como atividade humana autorrealizadora" (p. 65).

Concluindo esta parte, há que reconhecer as limitações inerentes à noção de exclusão, particularmente que ela não se constitui em novo paradigma, e que seu alcance fica no plano descritivo. Mesmo assim, avalia-se que essa categoria pode ser útil para caracterizar e quantificar determinadas situações educacionais, como a de crianças e adolescentes que, na faixa de escolarização obrigatória, não estejam frequentando escola, caso em que se poderia recorrer à noção de exclusão da escola, e a situação de crianças e adolescentes fortemente defasadas nos estudos em consequência de sucessivas reprovações, o que poderia ser tido como exclusão na escola. No plano explicativo, porém, haveria de trazer à baila dimensões do social, como as relações de classe, de gênero, étnico-raciais, regionais, geracionais, entre campo e cidade, etc.

\section{A perspectiva da desigualdade}

A segunda perspectiva teórica é a da desigualdade. A propósito, Henriques (2000, p. 1) inicia a Introdução à obra Desigualdade e pobreza no Brasil por ele organizada, dizendo que, no último ano do milênio, vozes e olhares estiveram "mergulhados na tentativa de entender por que somos campeões mundiais da desigualdade", título que ele considerava "vergonhoso, produto de uma herança de injustiça social que vem excluindo parte significativa da população brasileira do acesso a condições mínimas de dignidade e cidadania”. Está ali implícito que o agravamento da desigualdade pode levar à exclusão. Nos textos que compõem essa coletânea, a desigualdade se manifesta com as mais diversas caras: social, regional, racial, educacional, de renda, de gênero, entre os próprios pobres... 
Seguiram-se várias outras obras, entre as quais: Desigualdades raciais no Brasil: um balanço da intervenção governamental (JACCOUD; BEGHIN, 2002), focando as desigualdades raciais; Imagens da desigualdade (SCALON, 2004), oferecendo análises de atitudes e opiniões sobre as desigualdades; $A$ invisibilidade da desigualdade brasileira (SOUZA, 2006, p. 9), em que o organizador diz que o debate sobre a desigualdade brasileira se tem travado "sob o signo da fragmentação do conhecimento e da fragmentação da percepção da realidade" e que essa miopia da percepção seletiva e lacunar e sua consequente visão acrítica da realidade fizeram com que o país tenha "convivido com uma desigualdade naturalizada durante todo o processo de modernização".

Mas o tema da desigualdade não constituía novidade. Aliás, ele é tão antigo como o da luta pela igualdade. Basta lembrar Égalité des hommes et des femmes (Igualdade dos homens e das mulheres), de Marie de Gournay (1622); De l'égalité des deux sexes (Da igualdade entre os dois sexos), de 1673, de François Poulain de la Barre (2011), e Esboço de um quadro histórico dos progressos do espírito humano, de 1793-1794, do revolucionário francês marquês de Condorcet (1993). As duas primeiras obras, combatem a condição de desigualdade que pesava sobre as mulheres, reivindicando para estas a mesma educação que era dispensada aos homens; a terceira, combatendo a desigualdade em geral, inclusive de instrução, entre nações, entre cidadãos de um mesmo país e também entre homens e mulheres.

Mas, segundo a tese do sociólogo inglês Marshall (1967a), formulada na obra Cidadania, classe social e status, o tema da igualdade ou desigualdade social ganhou expressão com o surgimento dos direitos sociais no século XX, enquanto os direitos políticos haviam emergido no século XIX e os direitos civis, já no século XVIII. No entender de Schmitter (1967, p 10), no capítulo III dessa obra de Marshall, publicado originalmente em 1950 e que se tornou clássico, "o autor traça a interação entre a crescente igualdade política e a crescente desigualdade econômica". Note-se que a publicação original desse capítulo III da obra citada, de Marshall, se deu precisamente nos primeiros anos do Estado do Bem-Estar.

Marshall (1967a, p. 97), sociólogo de fé liberal, mas que chegou a sonhar com um "Estado socialista democrático" e que, em outra obra (MARSHALL, 1967b), desenvolveu a ideia de política social ${ }^{5}$, assim descreve os primeiros passos da luta contra a desigualdade:

O autor diz que estava empregando o termo política social "sempre com referência à política dos Governos relacionada à ação que exerça um impacto direto sobre o bem-estar dos cidadãos, ao proporcionar-lhes serviços ou renda" (MARSHALL, 1967b, p. 7), esclarecendo que o núcleo central da política social consiste no seguro social, assistência pública (ou nacional), serviços assistenciais médicos e sociais, política habitacional e, também, educação - esta, a ser assunto de outro volume da série. 
Iniciou-se um novo período no final do século XIX convenientemente assinalado pela pesquisa de Booth sobre a Vida e o Trabalho do Povo em Londres e pela Comissão Real sobre os Pobres em Idade Avançada. Assistiu-se ao primeiro grande avanço no campo dos direitos sociais, e isto acarretou mudanças significativas no princípio igualitário como expresso na cidadania. [...] Os componentes de uma vida civilizada e culta, originariamente o monopólio de poucos, foram, aos poucos, postos ao alcance de muitos. A diminuição da desigualdade fortaleceu a luta por sua abolição, pelo menos com relação aos elementos essenciais do bem-estar social (MARSHALL, 1967a, p. 88).

No que diz respeito, em particular, ao tema da igualdade de oportunidades educacionais, vale lembrar o que disse Coleman (1970, p. 9-24) no artigo The concept of equality of educational opportunity ( $O$ conceito de igualdade de oportunidade educacional). Os títulos do Relatório do evento e do artigo já deixam claro que, nos Estados Unidos, havia preocupação com o problema das desigualdades educacionais. Um dos aspectos mais interessantes é a verificação feita por Coleman, no mencionado texto, de que o conceito de igualdade de oportunidade havia variado muito no passado, que havia variado na época e continuaria a variar no futuro. E ele esclarece que a pesquisa havia sido concebida como um instrumento pluralístico, precisamente para dar conta dessa variedade de conceitos de igualdade de oportunidades educacionais. Evidentemente, essa preocupação resultava da constatação de que, no campo da educação, imperava a desigualdade. Há que lembrar, também, que o estudo que se acaba de citar surgiu nos Estados Unidos no pós-guerra, já do meio para o fim do Estado do BemEstar, um período absolutamente atípico na história do capitalismo-liberalismo.

Em obra publicada originalmente na França, em 1990, no texto "Sociologia das desigualdades de acesso à educação: principais orientações, principais resultados desde 1965”, Forquin (1995) apresentou uma síntese das pesquisas desenvolvidas sobre esse tema em diversos países nas décadas de 1960-1970. Nesse texto o autor tratava sucessivamente dos resultados de tais pesquisas, das acentuadas desigualdades de acesso e da relação entre essas desigualdades e a estrutura social, para, ao final, concluir pela fraqueza tanto das informações quanto das teorias examinadas: "nenhuma informação ou teoria sociológica está em condições de fundamentar completa e indubitavelmente uma política de educação" (FORQUIN, 1995, p. 71).

A propósito de igualdade e desigualdade, Alain Touraine (1999, p. 43) levanta uma questão que não pode ser ignorada: ao falar das "políticas reparadoras", 
das "ações afirmativas" ou, como ele prefere, da "discriminação positiva" ou simplesmente "equidade", ele propõe a substituição da ideia de igualdade pela de equidade, aduzindo a seguinte razão: "As medidas reparadoras que foram tomadas foram inspiradas pela equidade, quando o apelo muito geral à igualdade não reduz em nada as desigualdades reais." (TOURAINE, 1999, p. 43). Na realidade, o princípio revolucionário da igualdade, do século XVIII, assim como o da fraternidade, tem sido sempre pedra no sapato do liberalismo, especialmente em suas versões ultraliberais, como o neoliberalismo. A propósito, pode-se adiantar que o conceito de igualdade, real ou material, enunciado já nos albores da Revolução Francesa (CONDORCET, 1993), por oposição ao de igualdade, simplesmente formal, permitiria ir além do que Touraine (1999) chama de "apelo muito geral à igualdade". Quanto a isto, entende-se que não é o caso de se abrir mão do princípio (liberal!) da igualdade em favor do princípio da equidade, redivivo, este último, em trajes neoliberais.

Nos estudos de gênero, pode-se encontrar algo semelhante à proposta de Touraine, a saber, substituir a ideia de igualdade pela de equidade. Em Ciladas da diferença, Pierucci (2008, p. 35) observa que, "já no fim dos anos 70 e no decorrer dos 80 , se difundiu entre as feministas de todos os países uma discussão vivíssima e intelectualmente muito sofisticada, que se tornou conhecida como o debate da 'igualdade-versus-diferença"'. Para o autor, essa focalização da diferença:

Acaba roubando a cena da igualdade, posta sempre como antítese daquela no senso comum conservador, reativado nos tempos que correm por toda sorte de interpelações auto-referenciais e socialdarwinistas presentes nos discursos recentes das direitas identitárias (PIERUCCI, 2008, p. 47).

Em relação a essa questão, Cury (2002, p. 255) sustenta que "A dialética entre o direito à igualdade e o direito à diferença na educação escolar como dever do Estado e direito do cidadão não é uma relação simples"; que "É do reconhecimento da igualdade essencial de todas as pessoas do gênero humano que se nutriram de todas as teses da cidadania e da democracia"; e que "A defesa das diferenças, hoje tornada atual, não subsiste se levada adiante em prejuízo ou sob a negação da igualdade".

A esse respeito, assusta a leitura de La diversité contre l'Égalité (A diversidade contra a igualdade), a começar pelas primeiras palavras do livro: "INTRODUÇÃO: Liberdade, fraternidade... diversidade" (MICHAELS, 2009, p. 5), nas quais o termo diversidade toma o lugar do princípio revolucionário liberal da igualdade. Segundo o autor, "direita e esquerda podem hoje caminhar de mãos dadas na 
defesa daquilo que se tornou um novo cavalo-de-batalha: fazer com que as pessoas se sintam à vontade, não só com a sua diferença, mas também com a sua inferioridade" (MICHAELS, 2009, p. 92).

O fato é que a perspectiva da igualdade-desigualdade se tornou indispensável no estudo da educação, especialmente no país da desigualdade. No Brasil, conta-se com elevado número de estudos sobre educação em sua relação com uma ou mais das seguintes dimensões: gênero, raça-etnia, classe social, região, residência (cidade-campo), geração..., como em Hasenbalg (1979, p. 190-191), Barcelos (1993), Rosemberg e Piza (1996), Ferraro e Kreidlow (2004), Carvalho (2004), Arroyo (2010).

Em relação especificamente às desigualdades na educação, há que destacar a influência europeia, em particular a francesa, a começar por Les héritiers (Os herdeiros), obra clássica na Sociologia da Educação, de 1964, na qual se lê: "A cegueira diante das desigualdades escolares condena e autoriza a explicar todas as desigualdades, particularmente de sucesso escolar, como desigualdades naturais, desigualdades de dons." (BOURDIEU; PASSERON, 1985, p. 103). Esse tema das desigualdades escolares seria retomado em 1966, em artigo traduzido três décadas depois para o português, sob o título "A escola conservadora: as desigualdades frente à escola e à cultura", no qual o autor citado afirma que "não é suficiente enunciar o fato das desigualdades diante da escola, é necessário descrever os mecanismos objetivos que determinam a eliminação contínua das crianças desfavorecidas" (BOURDIEU, 1999, p. 41).

Decorrida década e meia desde Les héritiers, surgiu a obra L'inégalité des chances (A desigualdade de chances), de Boudon (1979), com a segunda parte dedicada à desigualdade das oportunidades perante o ensino.

Junto com isto, diversos artigos sobre desigualdades e desigualdades escolares, traduzidos do francês, marcaram presença em periódicos brasileiros, lembrandose aqui três publicados na Revista Brasileira de Educação: Enguita (1996), Dubet (2001) e Derouet (2002). Deste último vale lembrar a questão, por ele levantada, se se deve aceitar que um novo objetivo (a luta contra a exclusão) esteja substituindo a antiga luta pela igualdade, para, então, destacar-lhe a resposta: "A luta pela igualdade e a luta contra a exclusão remetem a modelos de sociedades diferentes" (DEROUET, 2002, p. 10).

Tudo isto para dizer da significativa presença da temática da desigualdade na pesquisa em educação, mas sem que se possa afirmar que esta tenha sido a 
perspectiva dominante na abordagem diagnóstica da escolarização no Brasil, muito menos que possam ser avaliados como satisfatórios os resultados obtidos de tais pesquisas, e os caminhos por elas sinalizados para as políticas educacionais.

Entende-se que a relevância, tanto teórica como político-prática, desta perspectiva em diagnósticos da escolarização está no fato de a desigualdade ter como o outro termo da antinomia o princípio da igualdade, princípio este que tem dividido teórica e politicamente o campo liberal, a ponto de aqueles que o priorizam, como Keynes, terem tido de se defender da acusação de socialismo ${ }^{6}$. A propósito, vale lembrar que, em 1793, os jacobinos franceses não haviam hesitado em recorrer à guilhotina para silenciar a voz da militante dos direitos da mulher, Olympe de Gouges, pela ousadia de imaginar que, à semelhança da Declaração dos direitos do homem e do cidadão, podia propor uma Declaração dos direitos da mulher, sobre o que se pode consultar os livros de Noack (1993) e Scott (2002, p. 49-104).

Concluindo esta parte, pode-se antecipar que o tema da igualdade-desigualdade no domínio da educação mantém relação estreita com o tema do direito-dívida educacional, a ser trabalhado na sequência, até porque a educação é um dentre os direitos sociais fundamentais, os quais "nasceram "abraçados ao princípio da igualdade" , entendida esta num sentido material” (SARLET, 2005, p. 56).

\section{A perspectiva da dívida educacional}

Não é novo o discurso sobre direito à educação. O que é relativamente novo, datando da Constituição Federal (CF) de 1988 (BRASIL, 1988), em seus artigos $6^{\circ}$ e $8^{\circ}$, é o direito à educação como direito humano fundamental social, no sentido de direito subjetivo de cada pessoa, com provisão de meios reais para cobrar a efetivação desse direito e de responsabilização da autoridade competente em caso de não oferta ou de oferta irregular do ensino obrigatório. O que pode continuar soando estranho é ouvir-se dizer que a não oferta ou a oferta irregular do serviço chamado educação coloca o Estado na condição de devedor, e a pessoa lesada, na condição de credora, pois, conforme se disse em estudo anterior (FERRARO, 2008) , “o conceito de dívida não oferece dificuldade. [...] já não é de tão fácil entendimento para as pessoas comuns, do povo, o discurso de que elas são credoras de educação escolar do Estado. Ou então, de que o Estado lhes deve tantos anos de escolarização" (p. 275).

\footnotetext{
É o que o autor citado faz no panfleto Am I a liberal? (Sou eu um liberal?), de 1925, pergunta que ele responde de forma inequívoca, dizendo que, no caso de uma luta de classes, ele seria encontrado, com certeza, "no campo da burguesia cultivada" (KEYNES, 1925, p. 38, .grifo do autor).
}

7 Expressão que o autor citado colheu de Bonavides (2017, p. 578). 
A distinção que Anísio Teixeira (1976) fazia - talvez melhor, a contradição que ele identificava - entre valores proclamados e valores reais nas instituições escolares brasileiras pode ser aplicada também à legislação constitucional na parte relativa à educação. Já em 1933, o conceituado constitucionalista brasileiro Pontes de Miranda (1933a, p. 7, grifos do autor) alertava: "Uma coisa é dizer-se que haverá escolas públicas, e outra, que todos terão escola pública". E prosseguia: "Há direitos declarados só verbalmente e de difícil reconhecimento, e direitos subjectivos, accionáveis. A distinção é essencial, para que se compreenda o nosso estudo." Em outro texto, o mesmo autor dizia: "A escola tem de ser para todos. Entre todos, e não entre os que tiverem dinheiro para se instruírem, é que se devem recrutar os dirigentes. A igualdade no início e no fim; a desigualdade só como meio, pelo indispensável valor técnico e organizador" (PONTES DE MIRANDA, 1933b, p. 70, grifos do autor).

Com efeito, não bastava a Constituição Imperial estabelecer que a instrução primária seria gratuita a todos os cidadãos; precisava, também, dizer em seu Art. 179, Inciso XXXII, como o Império garantiria isto e como os cidadãos poderiam fazer valer esse direito (BRASIL, 1824).

A primeira Constituição republicana, nos Art. $70, \S 1^{\circ}$ e Art. $72, \S 6^{\circ}$ (BRASI, 1891), foi omissa neste ponto, limitando-se a constitucionalizar a exclusão dos analfabetos do direito de voto, exclusão esta que datava da Lei Saraiva (BRASIL, 1881), e a assegurar a laicidade do ensino ministrado nos estabelecimentos públicos.

Foi a Constituição de 1934, no Art. 112, $\S 2^{\circ}$ e $\S 3^{\circ}$ (BRASIL, 1934), que, pela primeira vez no Brasil, reconheceu a educação como direito de todos e estabeleceu os princípios da obrigatoriedade do ensino primário e de sua gratuidade nas escolas públicas primárias, no entanto, sem definir instrumentos legais para o cidadão e a cidadã poderem assegurar tal direito, situação que não se alterou fundamentalmente nas constituições que se seguiram até a de 1988.

Foi somente nas ondas do movimento de redemocratização do país, depois de duas décadas e meia de ditadura, que se pôde ver consagrada, na Constituição da República Federativa do Brasil de 1988, a educação como direito no sentido apregoado por Pontes de Miranda, meio século antes, como aqui referido anteriormente. Com efeito, no artigo $6^{\circ}$ a educação encabeça a lista dos direitos sociais, e o artigo 208, no texto original de 1988, estabelece que o dever do Estado com a educação será efetivado mediante a garantia de: "I. ensino fundamental obrigatório e gratuito, assegurada, inclusive, sua oferta gratuita para todos os que a ele não tiveram acesso na idade própria; II. 
progressiva universalização do ensino médio gratuito"; e "VII. atendimento ao educando, no ensino fundamental, através de programas suplementares de material didático-escolar, transporte, alimentação e assistência à saúde" (BRASIL, 1988).

Mas o que mais interessa salientar aqui é o que consta nos dois primeiros parágrafos desse mesmo artigo 208, na redação original de 1988: " $\$ 1^{\circ}$. O acesso ao ensino obrigatório e gratuito é direito público subjetivo; $\S 2^{\circ}$. O não-oferecimento do ensino obrigatório pelo poder público, ou sua oferta irregular, importa em responsabilidade da autoridade competente" (BRASIL, 1988).

A Constituição de 1988 inovou, assim, na medida em que o direito à educação ultrapassou o caráter meramente declaratório e programático que tinha nas constituições anteriores, a partir da de 1934, para constituir-se em direito público subjetivo e, como tal, irrenunciável e exigível mediante a possibilidade real de responsabilização da autoridade competente, no caso de não oferta ou de oferta irregular do ensino obrigatório. Ou, como diz o Procurador Konzen (1995), até a CF/1988 "a educação era vista como uma necessidade e um dever. [...] A partir de 1988, o quadro normativo alterou-se completamente", e esclarece: "A Constituição Federal elevou a educação à categoria de direito público e, para a criança e o adolescente, a educação fundamental ao nível de direito público subjetivo e indisponível" (p. 12).

O que perturba, segundo o mesmo autor, não é a falta de normas, mas saber como fazê-las funcionarem, definir a responsabilidade ou o papel de cada um e identificar os instrumentos de exigibilidade. Na sequência, ele identifica os principais agentes da efetividade do direito à educação: primeiro, os pais, enquanto detentores do pátrio poder; depois, pela ordem, o Conselho Tutelar, o Ministério Público e a Tutela Judicial (KONZEN, 1995). Para Muniz (2002), o artigo 208 da CF, em seu $\S 2^{\circ}$, "responsabiliza civilmente o Estado por sua omissão ou por negligência na ação, assegurando àquele que foi prejudicado, por força do $\S 1^{\circ}$. do mesmo artigo, o direito subjetivo público de exigir dos Poderes Públicos a prestação a que estavam obrigados" (p. 87).

Foi nessa inovação constitucional que se fundamentou o conceito de dívida educacional, quantificável, por exemplo, com base no número de anos de escolarização obrigatória não cursados com aprovação (FERRARO, 2008). Assim, uma pessoa de 15 ou mais anos que, no momento de determinado levantamento censitário ou amostral, não tivesse concluído com aprovação as oito séries do Ensino Fundamental, teria crédito, perante o Estado, para cursar gratuitamente as 
séries faltantes (uma, duas, três...), até a conclusão dos oito anos de escolarização obrigatória então exigidos.

O Estado, por sua vez, se encontraria em situação de dívida de um, dois, três ou mais anos de escolarização gratuita em relação a essa pessoa. Isto significa dizer que a elevação do direito à educação, de um caráter meramente declaratório e programático para direito subjetivo irrenunciável e acionável, passa a significar que a não efetivação de anos de escolarização obrigatória, compreendendo hoje a Educação Infantil, o Ensino Fundamental e o Ensino Médio (BRASIL, 2009), produz dois efeitos imediatos e correlatos: de um lado, coloca cada jovem ou adulto, que não tenha concluído com aprovação toda a escolarização obrigatória, na condição de credor frente ao Estado, e de outro, coloca o Estado na condição de devedor de determinado número de anos de estudo em relação a essa pessoa. Foi com base nesse raciocínio que se pôde estimar a dívida educacional para o Brasil como um todo, com base no Censo Demográfico realizado no ano 2000 (FERRARO, 2008).

Para o cálculo da dívida educacional, tomou-se por base a população de 15 anos ou mais, classificada por grupos de idade (15 anos, 16 a 17 anos, 18 a 19 anos, 20 a 24 anos etc., até 70 anos ou mais) e por grupos de anos de estudo (sem instrução e menos de 1 ano, 1 a 3 anos, 4 a 7 anos e não determinados). Exemplifica-se o cálculo da dívida considerando-se apenas as pessoas de 15 anos de idade e tomando-se como critério/medida os 8 anos de escolarização obrigatória em vigor em 2000 :

a) número de pessoas de 15 anos de idade sem instrução ou com menos de 1 ano de estudo [138.971] X número de anos de estudo obrigatórios não realizados nesse grupo de anos de estudo = dívida educacional em anos de estudos não realizados [1.111.768];

b) número de pessoas de 15 anos de idade com 1 a 3 anos de estudo [489.250] X média estimada de anos de estudo não realizados nesse grupo de anos de estudo [6] = dívida educacional em anos de estudo não realizados [2.935.500];

c) número de pessoas de 15 anos de idade com 4 a 7 anos de estudo concluídos [1.857.603] X média estimada de anos de estudo não realizados nesse grupo [2,5 anos de estudo] = dívida educacional em anos de estudo não realizados [4.644.008] 
d) número de pessoas de 15 anos de idade com número de anos de estudo não determinados [41.610] X média estimada de anos de estudo não realizados [4] = dívida educacional em anos de estudo não realizados $[166.440]$.

e) Total da dívida educacional em anos de estudo não realizados, estimada para o grupo de pessoas de 15 anos de idade em 2000: $1.111 .768+2.935 .500+4.644 .008+166.440=8.857 .716$ anos de estudo devidos.

Se consideradas, por exemplo, todas as pessoas de 15 a 19 anos de idade, tendo sempre como parâmetro os 8 anos de escolarização obrigatória então em vigor, a dívida educacional no ano 2000 beirava os 35,6 milhões de anos de estudo não cursados com aprovação. Para toda a população de 15 ou mais anos, o montante da dívida alcançava o assombroso número de 325,5 milhões de anos de estudo devidos (FERRARO, 2008) ${ }^{8}$.

Obviamente, a perspectiva do direito/dívida mantém relação estreita com a perspectiva da igualdade/desigualdade, como se vê em texto da constitucionalista Piovesan (2005, p. 50-51), quando diz que, no Direito brasileiro, a CF 1988 "estabelece dispositivos que demandam a busca da igualdade material, que transcende a igualdade formal". E referindo-se à questão das relações étnico-raciais, a autora afirma: "Em um país em que os afrodescendentes são $64 \%$ dos pobres e $69 \%$ dos indigentes, faz-se necessária a adoção de ações afirmativas em benefício da população afrodescendente, em especial nas áreas da educação e do trabalho".

Mas há que considerar também duas mudanças importantes na legislação brasileira: primeiramente, a Lei $\mathrm{n}^{\mathrm{o}} 11.274$, de 6 de fevereiro de 2006 (BRASIL, 2006), que estendeu de oito para nove anos o Ensino Fundamental obrigatório e gratuito; a seguir, a Emenda Constitucional n ${ }^{\circ}$ 59, de 11 de novembro de 2009 - EC 59/2009 (BRASIL, 2009), que eleva progressivamente, até 2016, toda a Educação Básica Infantil, Fundamental e Média - à categoria de ensino obrigatório e gratuito e, portanto, à condição de direito público subjetivo.

A questão-chave, em relação aos direitos fundamentais sociais, entre eles o da educação, é posta, por exemplo, em termos de exigibilidade e efetividade (KONZEN, 1995) e de eficácia (SARLET, 2005). Mas, em tese de doutorado em educação, recentemente defendida na Universidade Federal do Rio Grande

\footnotetext{
${ }^{8}$ A atualização do cálculo da dívida educacional poderá ser objeto de novo estudo, possivelmente com base na Pesquisa Nacional por Amostra de Domicílios 2017.
} 
do Sul, Gehlen (2015, p. 189) desenvolveu estudo sobre direito ao Ensino Médio no Brasil à luz da teoria do garantismo, de Luigi Ferrajoli, concluindo que "o Garantismo Social, ao demandar a aplicabilidade dos direitos sociais em grau máximo vai além do direito público subjetivo", isto é, além da Educação Básica garantida pela $\mathrm{EC} \mathrm{n}^{\circ}$ 59/2009 (BRASIL, 2009).

Em relação a isto, talvez pela sua novidade e pela dificuldade de diálogo dos profissionais da educação com os do campo do direito, constitui-se ainda em desafio o desenvolvimento teórico e operacional dessa perspectiva do direito-dívida no que respeita à educação. Como já se disse antes, a força desta perspectiva de direito-dívida está no fato de que, enquanto direito humano social fundamental, o direito à educação está alinhado com e vinculado ao princípio da igualdade. Mas há também que lembrar que, pelo menos desde o século XVIII, a história tem andado, na imensa maior parte do tempo, fortemente inclinada para o lado que tem como sustentáculo o princípio da liberdade, não para aquele que tem como fundamento o princípio da igualdade. Em Porto Alegre ocorre a cada ano o Fórum da Liberdade. Seria algo inimaginável que as mesmas forças sociais viessem a organizar um Fórum da Igualdade!

O que se disse até aqui permite ver que as perspectivas da igualdade-desigualdade educacional e do direito-dívida educacional, longe de se oporem, complementam-se. Com isto, pode-se passar à quarta perspectiva teórica de diagnóstico da escolarização - a do fracasso escolar.

\section{A perspectiva do fracasso escolar}

A perspectiva do sucesso-fracasso escolar em diagnósticos da escolarização é, na opinião do autor deste artigo, a que se configura como a mais problemática, seja sob o aspecto teórico, seja sob aquele de suas implicações nas políticas educacionais e práticas pedagógicas.

No Brasil, a obra mais conhecida sobre o assunto é $A$ produção do fracasso escolar (PATTO, 1990), em que a autora apresenta um retrospecto crítico dos diferentes entendimentos do fracasso escolar a partir dos anos 1930, com apoio na produção veiculada na Revista Brasileira de Estudos Pedagógicos, seguido de pesquisa empírica numa escola situada na periferia da cidade de São Paulo. As conclusões a seguir transcritas atestam que as críticas da autora se dirigem às explicações do fracasso, não ao conceito em si de fracasso escolar:

1. As explicações do fracasso escolar baseadas nas teorias do déficit e da diferença cultural precisam ser revistas a partir 
do conhecimento dos mecanismos escolares produtores de dificuldades de aprendizagem. [...]

2. O fracasso da escola pública elementar é o resultado inevitável de um sistema educacional congenitamente gerador de obstáculos à realização de seus objetivos. [...]

3. O fracasso da escola elementar é administrado por um discurso científico que, escudado em sua competência, naturaliza esse fracasso aos olhos de todos os envolvidos no processo (PATTO, 1990, p. 340, 343, 346).

No mesmo ano da obra de Patto (1990), era publicado, na França, o texto "Abordagem sociológica do sucesso e do fracasso escolares: Desigualdades de sucesso escolar e origem social", de Forquin (1995), em obra por ele organizada, com tradução publicada no Brasil alguns anos depois. O autor começava dizendo que alguns estudos revelavam que o "fracasso escolar" não se repartia aleatoriamente em relação à origem social dos alunos, para, em seguida, evitando o termo fracasso escolar que ele havia colocado entre aspas, tratar do rendimento escolar na perspectiva do sucesso escolar. No entanto, pensa-se que o recurso à noção de sucesso, em vez de àquela de fracasso, não altera substancialmente essa perspectiva teórica de diagnóstico da escolarização. Afinal, sucesso e fracasso não são mais que elementos de uma antinomia. Cada um dos dois termos só é compreensível em relação ao seu antônimo.

Na realidade, também na França os termos fracasso e sucesso escolar não constituíam novidade. Charlot, por exemplo, em obra de 1976, com tradução publicada no Brasil em 1979 e recentemente reeditada (2013), mesmo que muito de passagem, questionava a propriedade desses termos, ao dizer que os fracassos da educação, em vez de serem considerados como fracassos pedagógicos e sociais, seriam "imputados à natureza da própria criança", da mesma forma que as diferenças de êxito cultural seriam vistas como "diferenças naturais" (CHARLOT, 2013, p. 200, 255).

Decorridos alguns anos desde a obra citada de Forquin (1995), tínhamos, no Brasil, a publicação de mais duas obras traduzidas do francês, ambas abordando o tema do fracasso, com destaque para a primeira. São elas: A pedagogia na escola diferenciada: fragmentos de uma sociologia do fracasso (PERRENOUD, 2001), do original francês de 1996, e Construir as competências desde a escola (PERRENOUD, 1999), do original francês de 1997. Desde o primeiro parágrafo 
da Introdução de A pedagogia na escola diferenciada, fica claro que a preocupação do autor é combater, de forma eficaz, o fracasso escolar e identificar-lhe as causas, sem preocupação com a propriedade do termo fracasso. Para ele, "a preocupação de lutar contra o fracasso escolar" teria surgido em diversos países nos anos 1960, mas sem que se tivesse elaborado uma "teoria correta daquilo que acontece" e sem que se houvesse tirado lições da experiência (PERRENOUD, 2001, p. 16). Em sua busca de explicação para o problema do fracasso escolar, o autor é movido pela seguinte questão: "se a escola dispõe de tanto poder sobre as pessoas, por que não consegue instruí-las?". Na pesquisa, ele identifica uma tríplice fabricação do fracasso": o currículo ou o caminho que se quer que os alunos percorram, o problema da indiferença às diferenças e o momento e modo de avaliação. (PERRENOUD, 2001, p. 19-21).

Já no começo do novo século, os espanhóis Marchesi e Gil (2004) reuniriam uma série de estudos, de autores de diferentes países, na coletânea Fracasso escolar: una perspectiva internacional, publicada em Madrid, em 2003, prontamente vertida para o português e publicada no ano seguinte pela Artmed.

O título Fracasso escolar não significa que todos os autores participantes da obra, inclusive os autores dos acréscimos feitos na edição brasileira, trabalhassem tranquilamente com o termo fracasso escolar. Com efeito, Marchesi, um dos organizadores, e Pérez iniciam o primeiro capítulo dizendo que o termo "fracasso escolar" é discutível, apontando as razões disto:

O termo "fracasso escolar" é inicialmente discutível. Em primeiro lugar, porque transmite a ideia de que o aluno "fracassado" não progrediu nada durante seus anos escolares, nem no âmbito de seus conhecimentos nem no de seu desenvolvimento pessoal e social, o que não corresponde em absoluto à realidade. Em segundo lugar, porque oferece uma imagem negativa do aluno, o que afeta a sua autoestima e sua confiança para melhorar no futuro. $\mathrm{O}$ mesmo acontece se a etiqueta de fracasso for aplicada à escola em seu conjunto porque não alcança os níveis que se espera dela. $\mathrm{O}$ conhecimento público desta avaliação pode incrementar suas dificuldades e distanciar dela alunos e famílias que poderiam contribuir para sua melhora. Em terceiro lugar, porque centra no aluno o problema do fracasso e parece esquecer a responsabilidade de outros agentes e instituições

Essa tríplice fabricação do fracasso escolar é retomada, aqui, pelo autor, de textos anteriores, como La triple fabrication de l'échec scolaire (PERRENOUD, 1989). 
como as condições sociais, a família, o sistema educacional ou a própria escola. (MARCHESI; PÉREZ, 2004, p. 17).

Os autores acrescentam que foram esses problemas que levaram ao emprego de outras expressões, como "alunos com baixo rendimento". Dizem também que talvez seja melhor trabalhar em torno de objetivos positivos na elaboração de políticas educacionais. Mesmo assim, eles continuaram valendo-se do termo fracasso escolar (MARCHESI; PÉREZ, 2004, p. 17).

Nessa mesma obra, Kovacs (2004) diz simplesmente que, apesar dos esforços, por pelo menos duas décadas, em superar o fracasso escolar, o problema persistia em todos os países da Organização para a Cooperação e Desenvolvimento Econômico (OCDE); Palacios (2004) recorre tranquilamente ao termo fracasso, e Hargreaves (2004) limita-se a distinguir entre fracasso na escola e fracasso da escola. Mas sempre fracasso.

Lahire (2004), por sua vez, usa sempre entre aspas as expressões fracasso escolar e êxito escolar, o que sugere que lhes põe restrições. Ademais, o título do capítulo: "A origem da desigualdade escolar" evidencia que o termo desigualdade escolar tem, para o autor, mais peso que o termo fracasso escolar. Em obra anterior (Sucesso escolar nos meios populares. As razões do improvável), Lahire (1995) também havia utilizado entre aspas os termos fracasso e sucesso. E isto, por entender que não era possível defini-los com exatidão, uma vez que seu sentido era produzido pela própria instituição escolar, variando, por isso, historicamente. Por seu lado, Rovira (2004, p. 82-90), mesmo que a expressão fracasso escolar lhe parecesse pouco acertada, por ser "um qualificativo demasiado simplista e, principalmente, muito negativo", não deixando espaço para nuances, entende que a mesma "já está reconhecida há muito e será difícil modificá-la", utilizando-a tranquilamente, por isso, em seu texto.

Também no Brasil, alguns trabalhos posteriores à obra de Patto (1990) revelam não haver uniformidade de entendimento no uso da expressão fracasso escolar. Spozati (2000), no texto "Exclusão social e fracasso escolar", articula as noções de fracasso e exclusão, inclusive a de desigualdade. Da mesma forma, o texto "Fracasso-sucesso: um pesadelo que perturba nossos sonhos", de Arroyo (2000). Em artigo sobre o estado da arte da pesquisa sobre o fracasso escolar no período 1991-2002, Angelucci et al. (2004) analisam teses e dissertações sobre o tema nas áreas de educação e psicologia, produzidas na Universidade de São Paulo, concluindo, entre outras coisas, que essas pesquisas continuam concebendo o fracasso escolar em chave psicologizante. 
Em estudo sobre juventude e escola, Dayrell et al. (2009, p. 92-97) dedicam algumas páginas à análise de dissertações e teses produzidas nos anos de 1999 a 2006 sobre o subtema do sucesso e fracasso escolar. Os autores sustentam que os estudos sobre fracasso escolar estavam diminuindo em número, tinham relação estreita com as temáticas das desigualdades educacionais e da repetência e evidenciavam influência marcante da sociologia da educação na França, particularmente de Charlot, de quem se dizia que procurava desconstruir a noção de fracasso escolar como objeto de análise.

Já o título "A persistência do fracasso escolar: desigualdade e ideologia", de Paula e Tfouni (2009), sugere articulação da perspectiva do fracasso com a da desigualdade. Queiroga (2010), por sua vez, numa revisão sobre o tema dentro de uma perspectiva crítica, busca identificar as condições históricas e sociais que deram origem a determinadas interpretações do fracasso escolar.

Também dentro da temática do fracasso escolar, no final dos anos 1990 chegou ao Brasil a questão do "fracasso dos meninos", da qual se tem ocupado de modo particular a pesquisadora Carvalho em sucessivos estudos (CARVALHO, 2001, 2003, 2004, 2012). Aqui, o tema do fracasso é atravessado principalmente pela relação de gênero, tendo como referência a inversão da histórica vantagem masculina pela crescente vantagem feminina em termos de vários indicadores educacionais. Nesse ponto, estima-se que o desafio para a pesquisa seja submeter a uma análise crítica os estudos sobre fracasso escolar, buscando-se esclarecer como tal perspectiva se diferencia das, se opõe às, ou se articula com as perspectivas da exclusão escolar, da desigualdade educacional e da dívida educacional. Parece que, em articulação com essa questão, estaria esta outra: Afinal, mudaram os meninos ou mudaram as meninas?

A questão, nesta parte, é, antes de tudo, de ordem teórica. O caminho parece ser o do confronto crítico entre as diversas perspectivas de diagnóstico da escolarização. A ideia é de que o recurso ao termo fracasso escolar leva a diagnósticos equivocados da escolarização, os quais, queira-se ou não, apoiam-se no pressuposto de que cada criança é a única responsável pelo seu desempenho. Às vezes, parte dessa responsabilidade é repassada para o professor ou professora, para a escola, para a família; nunca para o Estado. Entende-se que as noções de direito de cada cidadão ou cidadã e de obrigação do Estado e a possibilidade real de responsabilização da autoridade pública sugerem que se deveria deixar de lado as noções de sucesso e fracasso escolares.

\section{Conclusão}

O estudo desenvolvido neste artigo reforça a ideia de que a perspectiva do fracasso-sucesso escolar leva a diagnósticos equivocados da escolarização, 
precisamente por apoiar-se no pressuposto de que cabe inteiramente ao aluno ou aluna a responsabilidade pelo seu desempenho escolar. $O$ fato de, por vezes, se repassar parte dessa responsabilidade para a professora ou professor, para a escola, para a família, para a comunidade, (nunca para o Estado!), não altera substancialmente a ideia de que foi o aluno ou aluna que fracassou.

O estudo indica também que não se deveria tomar a perspectiva da exclusãoinclusão como um paradigma, seja em oposição, seja em substituição ao paradigma de classes, e que o recurso às categorias exclusão e inclusão deveria ser acompanhado de uma definição clara do sentido em que essas categorias são utilizadas na investigação. Há ainda que ter presente que a solução para o problema da exclusão escolar é deixar de excluir e não simplesmente incluir em escolas regidas pela lógica da exclusão.

Por fim, o estudo sugere que as perspectivas teóricas mais promissoras para diagnósticos da educação básica são as da igualdade-desigualdade educacional e do direito-dívida educacional. Isto, pela vinculação teórica entre essas duas perspectivas, porquanto a primeira é a própria expressão do princípio da igualdade, e a segunda tem nesse princípio o seu fundamento. Afinal, assim como os demais direitos fundamentais sociais, é no princípio da igualdade que o direito à educação encontra o seu fundamento. É claro, desde que se pense em igualdade material e não apenas formal! 


\title{
Primary and secondary schooling (K-12) diagnoses: $a$ confrontation of perspectives
}

\begin{abstract}
The paper addresses the potentialities and limits of four theoretical perspectives that have been evident in K-12 schooling diagnoses: the school success-failure, the school inclusion-exclusion, the educational equality-inequality, and the educational right-debt. The critical examination of the international scientific production from the 1960s on the subject, especially in Brazil and France, suggests that: a) the antinomy failure-success leads to mistaken diagnoses of schooling for having, or inducing to an assumption that the student is fully responsible for his/her educational achievement; b) the use of the antinomy exclusion-inclusion requires a clear definition of in which sense these categories will be used and that the realization that the solution for the exclusion is not merely including, but rather not excluding; c) lastly, the most promising theoretical perspectives are those of educational equality-inequality and educational right-debt, the former for being the expression of the equality principle and the latter for having its foundation on this principle.
\end{abstract}

Keywords: K-12 schooling, Diagnoses, Theoretical perspectives, Educational policy.

\section{Diagnósticos de la escolarización básica: una confrontación de perspectivas}

\section{Resumen}

Este articulo trata de las potencialidades y límites de cuatro perspectivas teóricas que están marcando presencia en diagnósticos de la escolarización básica: aquellas del suceso-fracaso escolar, de la inclusión-exclusión escolar, de la igualdad-desigualdad educacional y del derecho-deuda educacional. El examen crítico de la producción cientifica internacional a partir de los años 1960 sobre el tema, especialmente en Brasil y Francia, sugiere: a) que la antinomia fracaso-suceso lleva a diagnósticos equivocados de la escolarización, por tener o inducir a tener como presuposición que es del alumno o alumna toda la responsabilidad por su desempeño escolar; b) que el recurso a la antinomia exclusión-inclusión escolar requiere que se defina con clareza en qué sentido serán utilizadas estas categorías e que se tenga presente que la solución para la exclusión é dejar de excluir y no simplemente incluir; c) en fin, que las perspectivas teóricas más promisoras son las de la igualdad-desigualdad y del derecho-deuda educacional, la primera por ser expresión del principio de la igualdad y la segunda por tener en este principio su fundamento.

Palabras clave: Escolarización básica. Diagnósticos. Perspectivas teóricas. Política educacional. 


\section{Referências}

ANGELUCCI, C. B. et al. O estado da arte da pesquisa sobre o fracasso escolar (1991-2002): um estudo introdutório. Educação e Pesquisa, v. 30, n. 1, p. 51-72, abr. 2004. doi: http://dx.doi.org/10.1590/S1517-97022004000100004

ARROYO, M. G. Fracasso-sucesso: um pesadelo que perturba nossos sonhos. Em Aberto, Brasília, v. 17, n. 71, p. 33-40, jul. 2000. doi: http://dx.doi.org/10.24109/2176-6673.emaberto.17i71.2100

ARROYO, M. G. Políticas educacionais e desigualdades: à procura de novos significados. Educação e Sociedade, Campinas, v. 31, n. 113, p. 1381-1416, dez. 2010. doi: http://dx.doi.org/10.1590/S0101-73302010000400017

BARCELOS, L. C. Educação e desigualdades raciais no Brasil. Cadernos de Pesquisa, n. 86, p. 15-24, ago. 1993.

BONAVIDES, P. Curso de Direito Constitucional. 32. ed. atual. São Paulo: Melhoramentos, 2017.

BOURDIEU, P. A escola conservadora: as desigualdades frente à escola e À cultura. In: NOGUEIRA, M. A.; CATANI, A. (Org.). Pierre Bourdieu: escritos de educação. 2. ed. Petrópolis: Vozes, 1999. p. 39-64.

; CHAMPAGNE, P. Les exclus de l'interieur. Actes de la Recherche en Sciences Sociales, Paris, n. 91-92, p. 71-75, 1992. Disponível em: <http:// www.persee.fr/web/revues/home/prescript/article/arss_0335-5322_1992_ num_91_1_3008>. Acesso em: 21 jun. 2014.

Minuit, 1985.

; PASSERON, J.-C., Les héritiers: Les étudiants e la culture. Paris:

BOUDON, R. L'inégalité des chances: La mobilité sociale dans les sociétés industrielles, Paris: A. Colin, 1979. Collection Pluriel.

BRASIL. Constituição de 1824. Constituição Política do Império do Brazil, de 25 de março de 1824. Rio de Janeiro, RJ, 1824. Disponível em: <http://www2. camara.leg.br/legin/fed/consti/1824-1899/constituicao-35041-25-marco-1824532540-publicacaooriginal-14770-pl.html>. Acesso: 18 maio 2017.

. Constituição de 1891. Constituição da República dos Estados Unidos do Brasil, decretada e promulgada pelo Congresso Nacional Constituinte, em 24 de fevereiro de 1891. Rio de Janeiro, RJ, 1891. Disponível em: <http://www2. camara.leg.br/legin/fed/consti/1824-1899/constituicao-35081-24-fevereiro1891-532699-publicacaooriginal-15017-pl.html>. Acesso: 18 maio 2017. 
BRASIL. Constituição de 1934. Constituição da República dos Estados Unidos do Brasil, de 16 de julho 1934. Rio de Janeiro, RJ, 1934. Disponível em: <http:// www2.camara.leg.br/legin/fed/consti/1930-1939/constituicao-1934-16-julho1934-365196-publicacaooriginal-1-pl.html>. Acesso: 18 maio 2017.

. Decreto $N^{\circ} 3.029$ [Lei Saraiva], de 9 de janeiro 1881. Reforma a legislação eleitoral. Rio de Janeiro, RJ, 1881. Disponível em: <http://www2. camara.leg.br/legin/fed/decret/1824-1899/decreto-3029-9-janeiro-1881546079-publicacaooriginal-59786-pl.html>. Acesso em: 15 fev. 2015.

Constituição de 1988. Constituição da República Federativa do Brasil, de 5 de outubro de 1988. Brasília, DF: Senado, 1988. Disponível em: <http://www2.camara.leg.br/legin/fed/consti/1988/constituicao-1988-5outubro-1988-322142-publicacaooriginal-1-pl.html>. Acesso: 18 maio 2017.

. Lei $N^{\circ}$ 9.394, de 20 de dezembro de 1996. Estabelece as diretrizes e bases da educação nacional. Diário Oficial da União da República Federativa do Brasil, Brasília, DF, 23 dez. 1996. Disponível em: <http:// www2.camara.leg.br/legin/fed/lei/1996/lei-9394-20-dezembro-1996-362578publicacaooriginal-1-pl.html>. Acesso: 14 ago. 2015.

. Lei $N^{\circ} 11.274$, de 6 de fevereiro de 2006. Altera a redação dos arts. 29, 30, 32 e 87 da Lei $\mathrm{N}^{\circ} 9.394$, de 20 de dezembro de 1996, que estabelece as diretrizes e bases da educação nacional, dispondo sobre a duração de 9 (nove) anos para o ensino fundamental, com matrícula obrigatória a partir dos 6 (seis) anos de idade. Diário Oficial da União da República Federativa do Brasil, Brasília, DF, 7 mar. 2006. Disponível em: <http://www2.camara.leg.br/legin/ fed/lei/2006/lei-11274-6-fevereiro-2006-540875-publicacaooriginal-42341-pl. html>. Acesso: 18 maio 2017.

. Emenda Constitucional $n^{\circ}$ 59, de 11 de novembro de 2009. [...] dá nova redação aos incisos I e VII do art. 208, de forma a prever a obrigatoriedade do ensino de quatro a dezessete anos e ampliar a abrangência dos programas suplementares para todas as etapas da educação básica, e dá nova redação ao $\S$ $4^{\circ}$ do art. 211 e ao $\S 3^{\circ}$ do art. 212 e ao caput do art. 214, com a inserção neste dispositivo de inciso V. Diário Oficial da União da República Federativa do Brasil, Brasília, DF, 11 nov. 2009. Disponível em: http://www.planalto.gov.br/ ccivil_03/constituicao/emendas/emc/emc59.htm. Acesso: 18 maio 2017.

CARVALHO, M. P. Mau aluno, boa aluna? Como as professora avaliam meninos e meninas. Estudos Feministas, v. 9, n. 2, p. 554-574, 2001. doi: http://dx.doi.org/10.1590/S0104-026X2001000200013 
CARVALHO, M. P. Sucesso e fracasso escolar: uma questão de gênero. Educação e Pesquisa, São Paulo, v. 29, n. 1, p. 185-193, jun. 2003. doi:http://dx.doi.org/10.1590/S1517-97022003000100013

. Quem são os meninos que fracassam na escola? Cadernos de Pesquisa, v. 34, n. 121, p. 11-40, abr. 2004. doi: http://dx.doi.org/10.1590/S0100-15742004000100002

. Teses e dissertações sobre gênero e desempenho escolar no Brasil (1993 - 2007): um estado da arte. Pro-Posições, v. 23, n. 1 (67), p. 147-162, 2012. doi: http://dx.doi.org/10.1590/S0103-73072012000100010

CHARLOT, B. A mistificação pedagógica: realidades sociais e processos ideológicos na teoria da educação. São Paulo: Cortez, 2013.

COLEMAN, J. S. The concept of equality of educational opportunity. In: et al. Equal educational opportunity. 2. print. Cambridge: Harvard University Press, 1970. p. 9-24.

CONDORCET, J.-A.-N. de Caritat, Marquis de. Rapport et projet de décret relatifs à l'lorganization générale de instruction publique. Présentation à l'Assemblée Législative, 20 et 21 avril 1792. Paris, 1792. Disponível em: <http:// www.assemblee-nationale.fr/histoire/7ed.asp>. Acesso em: 31 maio 2008.

. Esboço de um quadro histórico dos progressos do espirito humano. Campinas: UNICAMP, 1993.

CURY, C. R. J. Direito à educação: direito à igualdade, direito à diferença. Cadernos de Pesquisa, n. 116, p. 245-262, jul. 2002. doi: http://dx.doi.org/10.1590/S0100-15742002000200010

DAYRELL, J. et al. Juventude e escola. In: SPOSITO, M. P. (Coord.). Estado da arte sobre juventude na pós-graduação brasileira: Educação, Ciências Sociais e Serviço Social (1999-2006). Belo Horizonte: Argvmentvm, 2009. p. 57-126.

DEROUET, J.-L. A sociologia das desigualdades em educação posta à prova pela segunda explosão escolar: deslocamento dos questionamentos e reinício da crítica. Revista Brasileira de Educação, Rio de Janeiro, n. 21, p. 5-16, dez. 2002. doi: http://dx.doi.org/10.1590/S1413-24782002000300002

DONZELOT, J.; ROMAN, J. Le déplacement de la question sociale. In: DONZELOT, J. (Dir.). Face a l'exclusion. Le modèle français. Paris: Esprit, 1991. p. 5-11. 
DUBET, F. L'exclusion scolaire: quelles solutions? In: PAUGAM, S. (Dir.). L'éxclusion: l'état des saviors. Paris: La Découverte, 1996. p. 497-506.

. As desigualdades multiplicadas. Revista Brasileira

de Educação, Rio de Janeiro, n. 17, p. 5-19, ago. 2001.

doi: http://dx.doi.org/10.1590/S1413-24782001000200002

. A escola e a exclusão. Cadernos de Pesquisa, n. 119, p. 29-45, jul. 2003.

ENGUITA, M. F. Os desiguais resultados das políticas igualitárias: classe, gênero e etnia na educação. Revista Brasileira de Educação, São Paulo, n. 3, p. 5-30, set./dez. 1996.

FERRARI, A. R. Analfabetismo no Brasil: tendência secular e avanços recentes. Resultados preliminares. Cadernos de Pesquisa, v. 52, p. 35-49, 1985.

. Escola e Produção do Analfabetismo no Brasil. Educação e Realidade, Porto Alegre, v. 12, n. 2, p. 81-96, 1987.

FERRARO, A. R. Diagnóstico da escolarização no Brasil. Revista Brasileira de Educação, São Paulo, n. 12, p. 22-47, dez. 1999.

. Direito à Educação no Brasil e dívida educacional. E se o povo cobrasse? Educação e Pesquisa, São Paulo, v. 34, n. 1, p. 273-289, 2008. doi: http://dx.doi.org/10.1590/S1517-97022008000200005

; KREIDLOW, D. Analfabetismo no Brasil: configuração e gênese das desigualdades regionais. Educação e Realidade, Porto Alegre, v. 29, n. 2, p. 179-200, dez. 2004.

FORQUIN, J.-C. Sociologia das desigualdades de acesso à educação: principais orientações, principais resultados desde 1965. In: (Org.). Sociologia da educação: dez anos de pesquisa. Petrópolis: Vozes, 1995. p. 19-78.

FOUCAULT, J.-B. Exclusion, inégalité et justice sociale. Esprit, Paris, n. 182, p. 47-55, juin 1992.

GEHLEN, M. E. O direito é concluir o ensino médio: na vida de todos, na voz dos operadores do direito, nos processos judiciais e na teoria do garantismo. 2015. 229 p. Tese (Doutorado em Educação) - Universidade Federal do Rio Grande do Sul, Porto Alegre, 2015. 
GOURNAY, M. Égalité des hommes et des femmes. 1622. Disponível em: $<\mathrm{http}$ ///fr.wikisource.org/wiki/\%C3\%89galit\%C3\%A9_des_Hommes_et_des_ Femmes $>$. Acesso em: 10 jan. 2015.

HARGREAVES, A. A política emocional no fracasso e no êxito escolar. In: MARCHESI, Á.; GIL, C. H. (Org.). Fracasso escolar: uma perspectiva multicultural. Porto Alegre: Artmed, 2004. p. 179-194.

HASENBALG, C. A. Discriminação e desigualdades raciais no Brasil. Rio de Janeiro: Graal, 1979.

HENRIQUES, R. (Org.). Desigualdade e pobreza no Brasil. Rio de Janeiro: IPEA, 2000.

JACCOUD, L. B.; BEGHIN, N. Desigualdades raciais no Brasil: um balanço da intervenção governamental. Brasília, DF: IPEA, 2002.

JANNUZZI, P. M. Indicadores para diagnóstico, monitoramento e avaliação de programas sociais no Brasil. Revista de Serviço Público, Brasília, v. 56, n. 2, p. 137-160, jun. 2005. doi: https://doi.org/10.21874/rsp.v56i2.222

KEYNES, J. M. Am I a liberal?. 1925. Disponível em: <http://es.paperblog.com/ john-maynard-keynes-am-i-a-liberal-1925-357931/>. Acesso em: 31 mar. 2015.

KONZEN, A. A. A educação é direito. In: SEMINÁRIO ESTADUAL, 1995, Porto Alegre. Caderno de textos: o direito é aprender. Porto Alegre: FAMURS, 1995. p. 12-16.

KOOGAN, A.; HOUAISS, A. Enciclopédia e dicionário ilustrado. 4. ed. Rio de Janeiro: Seifer, 1999.

KOVACS, K. O informe da OCDE sobre o fracasso escolar. In: MARCHESI, Á.; GIL, C. H. (Org.). Fracasso escolar: uma perspectiva multicultural. Porto Alegre: Artmed, 2004. p. 43-47.

LA BARRE, F. P. De l'égalité des deux sexes: De l'éducation des dames. De l'excelence des hommes. Éditon, présentation e notes para Marie-Frédéric Pellegrin. Paris: Libairie Philosophique J. Vrin, 2011.

LAHIRE, B. Sucesso escolar nos meios populares: as razões do improvável. São Paulo: Ática, 1995. p. 28-53. 
LAHIRE, B. As origens da desigualdade escolar. In: MARCHESI, Á.; GIL, C. H. (Org.). Fracasso escolar: uma perspectiva multicultural. Porto Alegre: Artmed, 2004. p. 69-75.

LENOIR, R. Les exclus, un Français sur dix. Paris : Le seuil, 1974.

MARCHESI, Á.; GIL, C. H. (Org.). Fracasso escolar: uma perspectiva multicultural. Porto Alegre: Artmed, 2004.

; PÉREZ, E. M. A compreensão do fracasso escolar. In:

GIL, C. H. (Org.). Fracasso escolar: uma perspectiva multicultural. Porto Alegre: Artmed, 2004. p. 17-33.

MARSHALL, T. H. Cidadania, classe social e status. Rio de Janeiro: Zahar, 1967a. . Política social. Rio de Janeiro: Zahar, 1967b.

MERRIEN, F.-X. État-Providence et lutte contre l'exclusion. In: PAUGAM, S. (Dir.). L'éxclusion: l'état des saviors: Paris: La Découverte, 1996. p. 417-427.

MÉSZÁROS, I. A educação para além do capital. 2. ed. rev. São Paulo: Boitempo, 2010.

MICHAELS, W. B. La diversité contre l'égalité. Paris: Raison d'agir, 2009.

MUNIZ, R. M. F. O direito à educação. Rio de Janeiro: Renovar, 2002.

NOACK, P. Olympe de Gouges: 1748-1993, courtisane et militante des Droits de la femme. Paris: Fallois, 1993.

OLIVEIRA, A. R. Marx e a exclusão. Pelotas, RS: Seiva, 2004.

PALACIOS, J. Relações família-escola: diferenças de status e fracasso escolar. In: MARCHESI, A.; GIL, C. H. (Org.). Fracasso escolar: uma perspectiva multicultural. Porto Alegre: Artmed, 2004. p. 76-81.

PATTO, M. H. S. A produção do fracasso escolar. São Paulo: T. A. Queiroz, 1990.

PAUGAM, S. (Dir.). L'éxclusion, l'état des saviors. Paris: La Découverte, 1996.

PAULA, F. S.; TFOUNI, L. V. A persistência do fracasso escolar: desigualdade e ideologia. Revista Brasileira de Orientação Profissional, São Paulo, v. 10, n. 2, p. 117-127, dez. 2009. Disponível em: <http:// pepsic.bvsalud.org/scielo.php?script $=$ sci_arttext\&pid $=\mathrm{S} 1679$ $33902009000200012 \& \operatorname{lng}=$ pt\&nrm=iso $>$. Acesso em: 16 dez. 2017. 
PERRENOUD, P. La triple fabrication de l'échec scolaire. Psychologie Française, $\mathrm{n}^{\circ} 34 / 4,1989$, p. 237-245. Disponível em: <http://www.unige.ch/fapse/SSE/ teachers/perrenoud/php_main/php_1992/1992_09.rtf $>$. Acesso em: 20 set. 2017.

. Construir as competências desde a escola. Porto Alegre: Artmed, 1999.

- A pedagogia na escola das diferenças: fragmentos de uma sociologia do fracasso. 2. ed. Porto Alegre: Artmed, 2001.

PIERUCCI, A. F. Ciladas da diferença. 2. ed., 1. reimpr. São Paulo: USP, Curso de Pós-Graduação em Sociologia, 2008.

PIOVESAN, F. Ações afirmativas na perspectiva dos direitos humanos. Cadernos de Pesquisa, São Paulo, v. 35, n. 124, p. 43-55, abr. 2005. doi: http://dx.doi.org/10.1590/S0100-15742005000100004

PONTES DE MIRANDA, [Francisco Cavalcanti]. Direito à Educação. Rio de Janeiro: Alba Limitada, 1933a. (Coleção dos 5 Direitos do Homem: Ciência e Trabalho).

. Os novos direitos do homem. Rio de Janeiro: Alba Limitada, 1933b. (Coleção dos 5 Direitos do Homem: Ciência e Trabalho).

QUEIROGA, M. S. N. O discurso do fracasso escolar na pedagogia crítica. Revista HISTEDBR On-line, Campinas, v. 10, n. 37, p. 20--219, mar. 2010. doi: http://dx.doi.org/10.20396/rho.v10i37.8639674

RIBEIRO, M. Exclusão: problematização do conceito. Educação e Pesquisa, São Paulo, v. 25, n. 1, p. 35-49, jun. 1999. doi: http://dx.doi.org/10.1590/S1517-97021999000100004

ROSEMBERG, F. Expansão da educação infantil e processos de exclusão. Cadernos de Pesquisa, São Paulo, n. 107, p. 7-40, jul. 1999.

; PIZA, E. Analfabetismo, gênero e raça no Brasil. Revista USP, São Paulo, n. 28, p. 110-121, fev. 1996. doi: http://dx.doi.org/10.11606/issn.23169036.v0i28p110-121

ROVIRA, J. M. P. Educação em valores e fracasso escolar. In: MARCHESI, Á.; GIL, C. H. (Org.). Fracasso escolar: uma perspectiva multicultural. Porto Alegre: Artmed, 2004. p. 82-90

SARLET, I. W. A eficácia dos direitos fundamentais. 5. ed. rev. e ampl. Porto Alegre: Livraria do Advogado, 2005. 
SCALON, C. (Org.). Imagens da desigualdade. Belo Horizonte: Ed. UFMG; Rio de Janeiro: IUPERJ/UCAM, 2004.

SCHMITTER, P. C. Introdução. In: MARSHALL, T. H. Cidadania, classe social e status. Rio de Janeiro: Zahar, 1967. p. 7-11.

SCOTT, J. W. A cidadã paradoxal: as feministas francesas e os direitos do homem. Florianópolis: Ed. Mulheres, 2002.

SPOZATI, A. Exclusão social e fracasso escolar. Em Aberto, Brasília, v. 17, n. 71, p. 21-32, jan. 2000. doi: http://dx.doi.org/10.24109/2176-6673.emaberto.17i71.2099

SOUZA, J. (Org.). A invisibilidade da desigualdade brasileira. Belo Horizonte: UFMG, 2006.

SPENCER, H. A sociedade é um organismo. In: CRUZ, M. B. Teorias sociológicas: os fundamentos e os clássicos (Antologia de textos). Lisboa: Fundação Calouste Gulbenkian, 1989. p. 193-205. v. 1.

TEIXEIRA, A. Valores proclamados e valores reais nas instituições escolares brasileiras. In: BRASIL. MEC. Educação no Brasil: textos selecionados. [Brasília, DF]: MEC, 1976. Disponível em: <http://pt.scribd.com/ doc/87849518/Teixeira-Anisio-Valores-proclamados-e-valores-reais-nasinstituicoes-escolares-brasileiras>. Acesso em: 22 jun. 2014.

THOMAS, H. La production des exclus. Politiques sociales e processus de désocialisation socio-politique, Paris: Presses Universitaires de France, 1997.

TOURAINE, A. Face à l'exclusion. Esprit, Paris, n. 169, p. 7-13, fév. 1991. . Como sair do liberalismo. Bauru, SP: EDUSC, 1999.

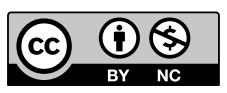

\section{Informações dos autores}

Alceu Ravanello Ferraro: Doutor em Ciências Sociais pela Pontifícia Universidade Gregoriana, Roma, 1969. Professor Titular aposentado do Departamento de Estudos Básicos da Faculdade de Educação da Universidade Federal do Rio Grande do Sul (UFRGS), em Porto Alegre, e, a partir de 2010, docente convidado do Programa de PósGraduação em Educação dessa mesma Universidade. Pesquisador do Conselho Nacional de Desenvolvimento Científico e Tecnológico - CNPq. Contato: aferraro@ufrgs.br 